\title{
Adding monounsaturated fatty acids to a dietary portfolio of cholesterol-lowering foods in hypercholesterolemia
}

\author{
David J.A. Jenkins MD, Laura Chiavaroli MSc, Julia M.W. Wong PhD RD, Cyril Kendall PhD, \\ Gary F. Lewis MD, Edward Vidgen BSc, Philip W. Connelly PhD, Lawrence A. Leiter MD, \\ Robert G. Josse MBBS, Benoît Lamarche PhD
}

Previously published at www.cmaj.ca

\section{ABSTRACT}

Background: Higher intake of monounsaturated fat may raise high-density lipoprotein (HDL) cholesterol without raising low-density lipoprotein (LDL) cholesterol. We tested whether increasing the monounsaturated fat content of a diet proven effective for lowering LDL cholesterol (dietary portfolio) also modified other risk factors for cardiovascular disease, specifically by increasing HDL cholesterol, lowering serum triglyceride and further reducing the ratio of total to HDL cholesterol.

Methods: Twenty-four patients with hyperlipidemia consumed a therapeutic diet very low in saturated fat for one month and were then randomly assigned to a dietary portfolio low or high in monounsaturated fatty acid for another month. We supplied participants' food for the two-month period. Calorie intake was based on HarrisBenedict estimates for energy requirements.

Results: For patients who consumed the dietary portfolio high in monounsaturated fat, HDL cholesterol rose, whereas for those consuming the dietary portfolio low in monounsaturated fat, HDL cholesterol did not change. The $12.5 \%$ treatment difference was significant $(0.12 \mathrm{mmol} / \mathrm{L}, 95 \%$ confidence interval $[\mathrm{Cl}] 0.05$ to $0.21, p=0.003)$. The ratio of total to HDL cholesterol was reduced by $6.5 \%$ with the diet high in monounsaturated fat relative to the diet low in monounsaturated fat $(-0.28,95 \% \mathrm{Cl}-0.59$ to $-0.04, p=$ 0.025). Patients consuming the diet high in monounsaturated fat also had significantly higher concentrations of apolipoprotein $\mathrm{Al}$, and their C-reactive protein was significantly lower. No treatment differences were seen for triglycerides, other lipids or body weight, and mean weight loss was similar for the diets high in monounsaturated fat $(-0.8 \mathrm{~kg})$ and low in monounsaturated fat $(-1.2 \mathrm{~kg})$.

Interpretation: Monounsaturated fat increased the effectiveness of a cholesterol-lowering dietary portfolio, despite statin-like reductions in LDL cholesterol. The potential benefits for cardiovascular risk were achieved through increases in $\mathrm{HDL}$ cholesterol, further reductions in the ratio of total to HDL cholesterol and reductions in C-reactive protein. (ClinicalTrials.gov trial register no. NCT00430430.)

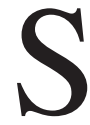
trategies that combine cholesterol-lowering foods or food components such as viscous fibres and plant sterols have been recommended to enhance the effectiveness of therapeutic diets low in saturated fat and cholesterol. ${ }^{1,2}$ Such dietary combinations (known as dietary portfolios) have resulted in substantial reductions in low-density lipoprotein (LDL) cholesterol ${ }^{3}$ and its apolipoprotein (apolipoprotein B), but the beneficial effects on high-density lipoprotein (HDL) cholesterol and its apolipoprotein (apolipoprotein AI) have been less apparent. ${ }^{4}$ Low concentrations of HDL cholesterol and apolipoprotein $\mathrm{AI}$ in the plasma and an elevated ratio of total to HDL cholesterol are recognized risk factors for cardiovascular disease..$^{5-9}$ Thus, dietary strategies that both lower total and LDL cholesterol and raise HDL cholesterol should have broad application. One method for increasing HDL cholesterol appears to be the use of monounsaturated fat, a key constituent of the Mediterranean diet, particularly when monounsaturated fat replaces dietary carbohydrates. ${ }^{10,11}$ Furthermore, increased intake of monounsaturated fat, through increased consumption of nuts and vegetable oil, has been associated with a reduced incidence of cardiovascular disease in cohort studies. ${ }^{12,13}$

We compared the effect on serum lipids of substituting $13.0 \%$ of total calories as carbohydrate with monounsaturated fatty acid in a dietary portfolio that has previously been shown, under controlled conditions, to be effective in lowering LDL cholesterol (by 28\%) and the ratio of total to HDL cholesterol (by 24\%). ${ }^{3}$ These reductions are similar to those seen with lovastatin $20 \mathrm{mg} / \mathrm{d}$ taken with the control diet. ${ }^{3}$

\section{Methods}

\section{Participants}

We recruited men and postmenopausal women with mild to moderate hypercholesterolemia from the Clinical Nutrition and Risk Factor Modification Centre at St. Michael's Hospital, Toronto, Ontario, and through newspaper advertisements. We

From the Clinical Nutrition and Risk Factor Modification Centre (Jenkins, Chiavaroli, Wong, Kendall, Vidgen, Leiter), the Division of Endocrinology and Metabolism, Department of Medicine (Connelly, Leiter, Josse), and the Keenan Research Centre, Li Ka Shing Knowledge Institute (Jenkins, Connelly), St. Michael's Hospital, Toronto, Ont.; the Department of Nutritiona Sciences, Faculty of Medicine (Jenkins, Chiavaroli, Wong, Kendall), the Division of Endocrinology, Department of Medicine (Lewis), the Department of Medicine, Faculty of Medicine (Leiter, Josse), the Department of Physiology (Lewis) and the Department of Laboratory Medicine and Pathobiology (Connelly), University of Toronto, Toronto, Ont.; the College of Pharmacy and Nutrition (Kendall), University of Saskatchewan, Saskatoon, Sask.; the Division of Clinical Investigation and Human Physiology (Lewis), Toronto General Hospital, Toronto, Ont.; and the Institute of Nutraceuticals and Functional Foods (Lamarche), Université Laval, Québec, Que.

CMAJ 2010. DOI:10.1503/cmaj.092128 
selected participants with previously recorded LDL cholesterol levels above $4.1 \mathrm{mmol} / \mathrm{L} .{ }^{1,2} \mathrm{We}$ excluded potential participants with a history of cardiovascular disease, untreated hypertension (blood pressure $>140 / 90 \mathrm{~mm} \mathrm{Hg}$ ), diabetes mellitus, or renal or liver disease and those taking medications known to influence serum lipids, apart from stable doses of thyroxine. We asked patients to maintain their intake of medications and supplements constant over the course of the study and to advise us if any alterations were made. We provided iron supplementation (ferrous gluconate $7 \mathrm{mg}$ three times daily) to participants whose prestudy ferritin level was below $50 \mu \mathrm{g} / \mathrm{L}$.

\section{Study protocol}

We conducted this randomized parallel study between August 2007 and April 2009. Participants were already following a low-fat diet, and we provided a metabolically controlled dairy and whole-grain cereal diet very low in saturated fat, for a one-month run-in stabilization period. We then randomly assigned patients to consume either a dietary portfolio high in monounsaturated fatty acids or a conventional dietary portfolio (low in monounsaturated fatty acids) for a second month. During the last week of the month on the metabolically controlled run-in stabilization diet and the portfolio diet period that followed, we undertook kinetic studies with stable isotopically labelled leucine to assess the metabolism of very low-density lipoprotein triglyceride and apolipoprotein AI. The results of these kinetic studies will be reported later.

At two-week intervals, we obtained blood samples (after 12hour overnight fasts) and determined body weight, and a single observer (L.C.) measured blood pressure three times in the nondominant arm with an automated digital blood pressure monitor (OMRON Healthcare Inc., Vernon Hills, USA). We obtained a seven-day diet history for the week before the two-month metabolic treatment period. During the four-week diet periods, participants completed and returned menu checklists at weekly intervals, along with seven-day exercise records; dieticians checked the menu checklists and verified that exercise was held constant. We calculated exercise in terms of metabolic equivalent of tasks. ${ }^{14}$ At weekly intervals, participants recorded their overall feeling of satiety according to a nine-point bipolar semantic scale, in which -4 was extremely hungry, 0 was neutral and +4 was uncomfortably satiated.

During the first two weeks of the four weeks on the therapeutic diet with very low saturated fat (run-in stabilization period), the statistician (E.V.), working at a location separate from the clinic and using a random number generator and other software, randomly assigned participants to a dietary portfolio with low or high monounsaturated fat and stratified them on the basis of sex and LDL cholesterol $(<4.2 \mathrm{mmol} / \mathrm{L}$ or $\geq 4.2 \mathrm{mmol} / \mathrm{L})$. The dietitians were not blinded to the diet, because they were responsible for patients' diets and for checking dietary records. The laboratory staff responsible for the biochemical analyses described below were blinded to treatment and received samples labelled only with name codes and dates. The study was approved by the ethics committees of the University of Toronto, St. Michael's Hospital and the Natural Health Products Directorate of Health Canada. We obtained written informed consent from all participants. Participants were offered no financial compensation for participation in the study. The ClinicalTrials.gov trial register number was NCT00430430.

\section{Diets}

The diets for the eight-week study period were based on estimated caloric requirements according to the Harris-Benedict

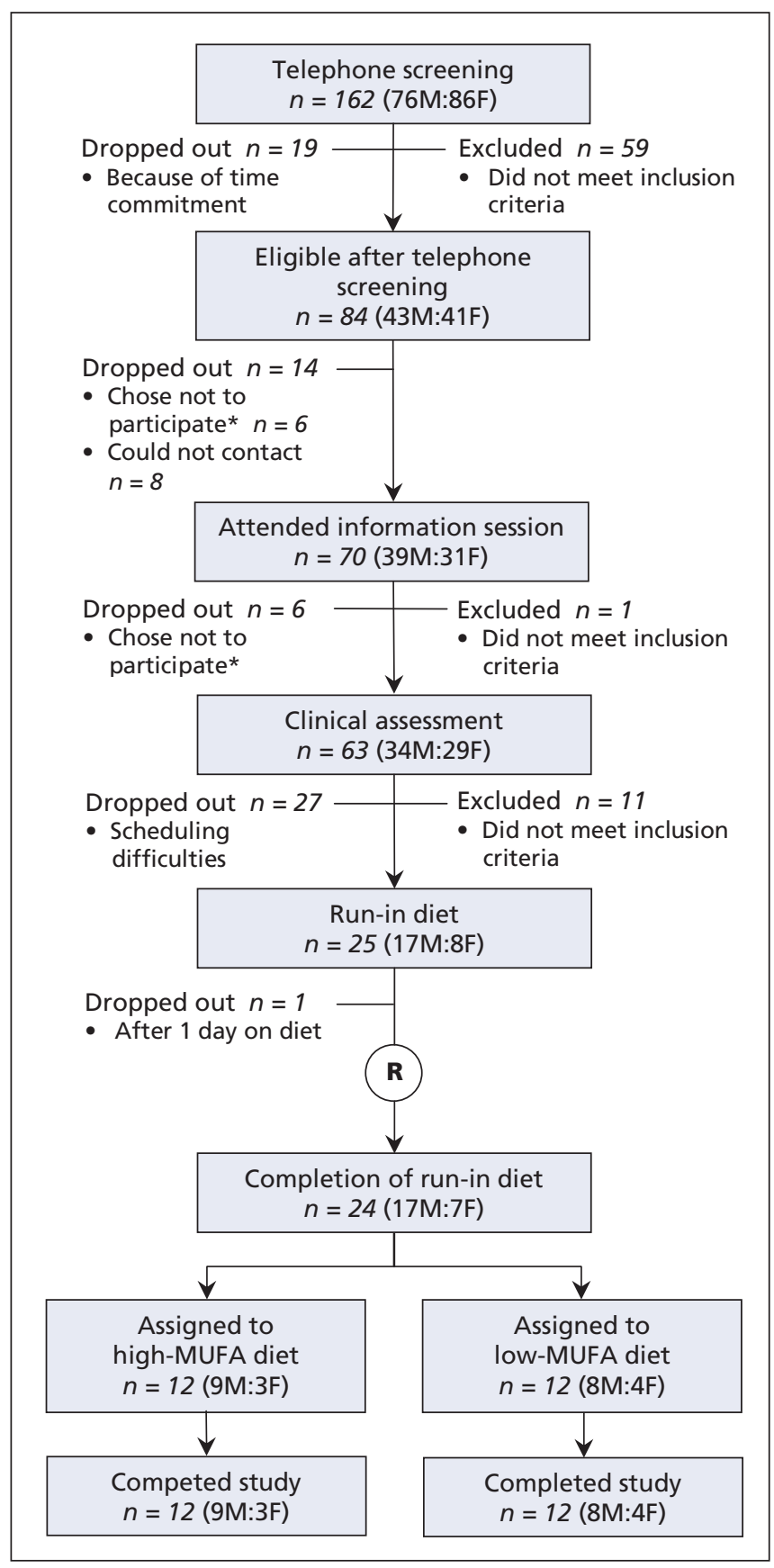

Figure 1: Flow of patients through the study. * Of the 12 people who chose not to participate, four had a medical issue, two wanted to lose weight, one was not willing to stop statin therapy, one was not willing to stop vitamin supplements, one was not willing to give blood samples for analysis, one was not willing to undergo kinetics testing, one had a family issue, and one was not interested. $\mathrm{F}=$ female, $\mathrm{M}=$ male, MUFA = monounsaturated fatty acid, $\mathrm{R}=$ randomization. 
equation, including an activity factor. ${ }^{15,16}$ All diets were vegetarian. For the diet high in monounsaturated fatty acids, we replaced $13.0 \%$ of dietary calories as carbohydrate with monounsaturated fatty acids, given in the form of a sunflower oil containing $80 \%$ monounsaturated fatty acids, with the option for a partial exchange with avocado. The aim of the dietary portfolio was to provide $1.0 \mathrm{~g}$ of plant sterols per $1000 \mathrm{kcal}$ of diet in a plant sterol ester-enriched margarine (Flora Pro-Activ, Unilever, London, UK) with a minimum of $2 \mathrm{~g} / \mathrm{d}$ and a maximum of $3 \mathrm{~g} / \mathrm{d}$ of plant sterols. The diet also provided $10.3 \mathrm{~g}$ of viscous fibre per $1000 \mathrm{kcal}$ of diet from oats, barley, psyllium, eggplant and okra; $20 \mathrm{~g}$ of soy protein per $1000 \mathrm{kcal}$ as soy milk, tofu and soy meat analogues; and $21.5 \mathrm{~g}$ of whole almonds per $1000 \mathrm{kcal}$ of diet.
The dietary portfolio included two eggs per week to balance the saturated fat and dietary cholesterol in the control diet.

To achieve low saturated fat and high fibre, the run-in stabilization diet, eaten in the first month and based on the National Cholesterol Education Program Adult Treatment Panel III guidelines, ${ }^{2}$ included skim milk, fat-free cheese and yogurt, egg substitute and liquid egg white, whole-grain breakfast cereals ( $2.5 \mathrm{~g}$ fibre per $1000 \mathrm{kcal}$ of diet) and whole-grain bread ( $3 \mathrm{~g}$ fibre per $1000 \mathrm{kcal}$ of diet).

We offered participants seven-day rotating menus, with foods delivered by courier at weekly intervals (Appendix 1, available at www.cmaj.ca/cgi/content/full/cmaj.092128 /DC1). We have previously described both diets in detail.

Table 1: Baseline characteristics of 24 study participants*

\begin{tabular}{|c|c|c|c|c|c|c|}
\hline \multirow{3}{*}{$\begin{array}{l}\text { Characteristic } \\
\text { Age, yr }\end{array}$} & \multicolumn{3}{|c|}{ High-MUFA portfolio, $n=12$} & \multicolumn{3}{|c|}{ Low-MUFA portfolio, $n=12$} \\
\hline & \multicolumn{2}{|c|}{ Mean (SD) $\dagger$} & \multirow{2}{*}{$\begin{array}{l}\text { Range } \\
42-68\end{array}$} & \multicolumn{2}{|c|}{ Mean (SD) $\dagger$} & \multirow{2}{*}{$\begin{array}{l}\text { Range } \\
38-69\end{array}$} \\
\hline & 54.7 & $(8.0)$ & & 55.5 & $(11.0)$ & \\
\hline Sex, male:female & \multicolumn{2}{|c|}{$9: 3$} & \multicolumn{4}{|c|}{$8: 4$} \\
\hline Weight, kg & 83.1 & $(14.1)$ & $62-113$ & 79.9 & $(6.2)$ & $71-89$ \\
\hline BMI & 29.0 & $(4.3)$ & $25-36$ & 28.8 & $(1.8)$ & $26-32$ \\
\hline \multicolumn{7}{|l|}{ Cholesterol, $\mathrm{mmol} / \mathrm{L}$} \\
\hline Total & 6.3 & $(0.7)$ & $5.4-7.7$ & 6.2 & (0.9) & $5.2-7.6$ \\
\hline LDL & 4.3 & $(0.7)$ & $3.5-5.6$ & 4.2 & $(0.8)$ & $3.3-5.2$ \\
\hline HDL & 1.14 & $(0.27)$ & $0.73-1.66$ & 1.22 & $(0.10)$ & $1.03-1.37$ \\
\hline Triglycerides & 1.9 & $(0.7)$ & $1.0-3.5$ & 1.6 & $(0.6)$ & $0.8-2.8$ \\
\hline \multicolumn{7}{|l|}{ Blood pressure, $\mathrm{mm} \mathrm{Hg}$} \\
\hline Systolic & 126.6 & $(10.5)$ & $109-142$ & 121.3 & $(9.9)$ & $105-142$ \\
\hline Diastolic & 76.6 & $(9.9)$ & 57-91 & 73.5 & $(7.3)$ & $61-89$ \\
\hline Exercise, METs & 21.7 & $(18.1)$ & $1.5-55.0$ & 23.2 & (17.3) & $2.3-55.1$ \\
\hline \multicolumn{7}{|l|}{ Medications, no. of participants } \\
\hline For blood pressure & \multicolumn{2}{|c|}{3} & & \multicolumn{2}{|l|}{2} & \\
\hline Thyroxine (0.08 mg once daily) & \multicolumn{2}{|c|}{0} & & \multicolumn{2}{|l|}{1} & \\
\hline ASA (81 mg) & \multicolumn{2}{|c|}{1} & & \multicolumn{2}{|c|}{3} & \\
\hline \multicolumn{7}{|l|}{ Supplements } \\
\hline Iron (7 mg, 3 times daily) $\ddagger$ & \multicolumn{2}{|c|}{7} & & \multicolumn{2}{|l|}{9} & \\
\hline Multivitamin & \multicolumn{2}{|c|}{2} & & \multicolumn{2}{|c|}{2} & \\
\hline Calcium & \multicolumn{2}{|c|}{3} & & \multicolumn{2}{|c|}{5} & \\
\hline Vitamin D & \multicolumn{2}{|c|}{2} & & \multicolumn{2}{|c|}{3} & \\
\hline Glucosamine and chondroitin & \multicolumn{2}{|c|}{1} & & \multicolumn{2}{|c|}{1} & \\
\hline \multicolumn{7}{|l|}{$\begin{array}{l}\text { Statins discontinued before study, } \\
\text { no. of participants§ }\end{array}$} \\
\hline Rosuvastatin, $5 \mathrm{mg}$ & \multicolumn{2}{|c|}{1} & & 0 & & \\
\hline Rosuvastatin, $10 \mathrm{mg}$ & 1 & & & 2 & & \\
\hline Rosuvastatin, 20 mg & 0 & & & 1 & & \\
\hline Atorvastatin, $20 \mathrm{mg}$ & 1 & & & 0 & & \\
\hline
\end{tabular}

Note: $\mathrm{ASA}=$ acetylsalicylic acid, BMI = body mass index, $\mathrm{HDL}=$ high-density lipoprotein, $\mathrm{LDL}=$ low-density lipoprotein, $\mathrm{MET}=$ metabolic equivalent of tasks (index expressing energy cost of physical activities, as multiples of resting metabolic rate), MUFA = monounsaturated fatty acid, SD = standard deviation.

*No significant differences between groups with dietary portfolios high and low in monounsaturated fatty acids. tUnless indicated otherwise.

$\ddagger$ Provided as part of the study for those with ferritin level $<50 \mu \mathrm{g} / \mathrm{L}$ at time of screening

$\S$ Participants who were taking statins at the time of enrolment were asked to discontinue these drugs two weeks before starting the study, with physician's consent. 
We assessed dietary compliance on the basis of completed weekly checklists and return of uneaten food items.

\section{Laboratory analyses}

We have detailed our analytical methods previously. ${ }^{3} \mathrm{We}$ labelled all serum samples from a given individual by code and analyzed them in the same batch. Serum lipids were analyzed in the J. Alick Little Lipid Research Laboratory, Toronto, Ontario. Total cholesterol, triglyceride and HDL cholesterol were analyzed with the Cobas 501 module and the manufacturer's HDL C3 reagents for homogeneous HDL determination (Roche, Laval, Quebec). The method was standardized by the Centers for Disease Control and Prevention. ${ }^{17}$ Apolipoprotein AI, apolipoprotein B and high-sensitivity Creactive protein were measured with a $\mathrm{BN}$ ProSpec analyzer and the manufacturer's reagents (Siemens, Mississauga, Ontario). We analyzed diets using a software program based on US Department of Agriculture data.

\section{Statistical analysis}

We calculated results as means with standard deviations (SDs) or 95\% confidence intervals (CIs). The study was an efficacy study, with serum HDL cholesterol and triglycerides as the primary outcomes in the direct comparison of dietary portfolios with high and low monounsaturated fatty acids. Reductions in the rates of production and fractional catabolic rates for apolipoprotein $\mathrm{B}_{100}$

Table 2: Macronutrient composition of the study diet, as consumed by 24 participants*

\begin{tabular}{|c|c|c|c|}
\hline \multirow[b]{2}{*}{ Composition } & \multicolumn{3}{|c|}{ Mean daily $\%$ of calories $\dagger$} \\
\hline & $\begin{array}{c}\text { NCEP } \\
\text { control } \\
\text { diet, } \\
n=24 \ddagger\end{array}$ & $\begin{array}{c}\text { High- } \\
\text { MUFA } \\
\text { portfolio, } \\
n=12\end{array}$ & $\begin{array}{c}\text { Low- } \\
\text { MUFA } \\
\text { portfolio, } \\
n=12\end{array}$ \\
\hline Calories, kcal & $2441.7^{\mathrm{a}}$ & $2356.4^{a}$ & $2345.3^{a}$ \\
\hline Protein & $20.4^{a}$ & $20.5^{a}$ & $21.7^{\mathrm{b}}$ \\
\hline Soy protein & $0.0^{\mathrm{a}}$ & $7.7^{b}$ & $8.3^{c}$ \\
\hline Available carbohydrate & $51.9^{a}$ & $33.9^{b}$ & $49.1^{c}$ \\
\hline \multicolumn{4}{|l|}{ Fibre, g/1000 kcal } \\
\hline Dietary & $20.1^{\mathrm{a}}$ & $32.7^{\mathrm{b}}$ & $35.5^{c}$ \\
\hline Viscous & $0.0^{\mathrm{a}}$ & $9.3^{b}$ & $11.0^{c}$ \\
\hline Fat & $27.5^{\mathrm{a}}$ & $45.6^{b}$ & $29.3^{c}$ \\
\hline Saturated fatty acids & $4.6^{a}$ & $6.7^{b}$ & $4.7^{\mathrm{a}}$ \\
\hline $\begin{array}{l}\text { Monounsaturated } \\
\text { fatty acids }\end{array}$ & $10.6^{a}$ & $25.9^{b}$ & $12.9^{c}$ \\
\hline $\begin{array}{l}\text { Polyunsaturated fatty } \\
\text { acids }\end{array}$ & $9.9^{\mathrm{a}}$ & $11.7^{\mathrm{b}}$ & $11.0^{\mathrm{b}}$ \\
\hline $\begin{array}{l}\text { Dietary cholesterol, } \\
\mathrm{mg} / 1000 \mathrm{kcal}\end{array}$ & $38.9^{\mathrm{a}}$ & $31.8^{\mathrm{b}}$ & $29.9^{c}$ \\
\hline Alcohol & $0.14^{a}$ & $0.38^{b}$ & $0.00^{c}$ \\
\hline
\end{tabular}

Note: MUFA = monounsaturated fatty acid, NCEP = National Cholesterol Education Program Adult Treatment Panel III. ${ }^{2}$

*Unless indicated otherwise.

tDifferent superscript letters for data in a given row indicate significant differences between treatments $(p<0.05)$ as assessed by analysis of covariance.

¥One-month run-in stabilization period. and apolipoprotein AI were the primary outcomes in the kinetics part of the study, which will be reported later. We compared dietary portfolios with high and low monounsaturated fatty acids by means of a repeated-measures analysis using mixed-effects models based on six- and eight-week (treatment) values, adjusted for values at week 4 (dietary portfolio baseline) and for time (week). ${ }^{18}$ We performed the mixed-effects analysis with $R$ version $2.10 .1^{19}$ and the contributed $R$ package $l m e 4 .{ }^{20}$ The intervals for the effects were $95 \%$ highest posterior density intervals obtained from Markov Chain Monte Carlo simulation of the posterior modes. ${ }^{21}$ The $p$ values were also obtained from the Markov Chain Monte Carlo results.

For descriptive purposes, the within-treatment changes (weeks 6 and 8) are also expressed in the text as percentages of baseline (week 4).

\section{Power calculation}

Assuming a $7.0 \%$ difference in the change in HDL cholesterol between treatments and an 8\% SD of effect, with $\alpha=$ 0.05 and $1-\beta=0.8$, we originally calculated that 12 participants would be required per treatment group, for a total of 24 . Subsequent recalculation of participant numbers using the same data gave a figure of 42 participants (21 per group).

\section{Results}

After telephone screening and clinical assessment, we assigned 24 healthy participants with hyperlipidemia (17 men and 7 postmenopausal women) to either the high or the low monounsaturated fatty acid arm of the study (Figure 1). Their baseline characteristics were similar (Table 1). Six of the participants, three in each group, had been taking statins. With approval from their respective primary care physicians, these participants discontinued statin therapy, as required by the study protocol, at least two weeks before the study began.

Compliance, expressed as the percentage of prescribed calories recorded as eaten over the four-week period, was high for all three diets: $93 \%$ for the metabolically controlled run-in stabilization diet with very low saturated fat, $95 \%$ for the dietary portfolio with high monounsaturated fat and $91 \%$ for the dietary portfolio with low monounsaturated fat. Macronutrient analysis based on food consumed (Table 2) confirmed the difference in monounsaturated fat content between the study arms. At the end of each treatment period, all participants believed that they were eating as much food as they could without experiencing discomfort (where discomfort was defined as a satiety rating of 4.0). The mean satiety ratings were 2.1 for the run-in diet, 2.3 for the dietary portfolio with high monounsaturated fat and 2.0 for the dietary portfolio with low monounsaturated fat. Participants lost a similar amount of weight with the run-in stabilization diet and both subsequent one-month treatments $(-1.1 \mathrm{~kg}$ with run-in diet, $-0.8 \mathrm{~kg}$ with dietary portfolio high in monounsaturated fat, -1.2 $\mathrm{kg}$ with dietary portfolio low in monounsaturated fat) (Table 3).

\section{Blood lipids and C-reactive protein}

No differences in baseline measurements (before the run-in diet low in saturated fat) or in changes during the run-in period were seen between the participants who were subse- 
quently assigned to dietary portfolios with high and low monounsaturated fat (Figure 2).

Participants consuming the dietary portfolio high in monounsaturated fat, but not those consuming the dietary portfolio low in monounsaturated fat, had significant increases in HDL cholesterol $(12.5 \%$ treatment difference; $0.12 \mathrm{mmol} / \mathrm{L}, 95 \% \mathrm{CI}$ 0.05 to 0.21$)$ and apolipoprotein $\mathrm{AI}(10.1 \%$ treatment difference; $0.12 \mathrm{mmol} / \mathrm{L}, 95 \%$ CI 0.05 to 0.18 ) (Table 3, Figure 2). Participants consuming the dietary portfolio high in monounsaturated fat also had significant reductions in the ratio of total to HDL cholesterol ( $-6.5 \%$ treatment difference; -0.28 , 95\% CI -0.59 to -0.04 ), apolipoprotein B to apolipoprotein AI ( $-5.1 \%$ treatment difference; $-0.04,95 \% \mathrm{CI}-0.07$ to 0.00$)$ and high-sensitivity C-reactive protein $(-76.4 \%$ treatment difference; $-1.27 \mathrm{mg} / \mathrm{L}, 95 \% \mathrm{CI}-1.76$ to -0.39) (Appendix 2, available at www.cmaj.ca/cgi/content/full/cmaj.092128/DC1).

There were no between-treatment differences in terms of changes in triglycerides, LDL cholesterol or apolipoprotein B. However, for both dietary portfolios, there were significant within-treatment reductions in LDL cholesterol $(-19 \%$ with high and $-21 \%$ with low monounsaturated fat) and apolipoprotein $\mathrm{B}(-16 \%$ with high and $-18 \%$ with low monounsaturated fat) (all $p<0.001)$.

\section{Blood pressure}

We observed no significant treatment-related differences in blood pressure (Table 3).

\section{Drop-outs and adverse events}

No participants withdrew from the study after the randomization, which occurred during the first and second weeks of the run-in phase. One participant withdrew at the time of the first control breakfast (i.e., before randomization) because of the perceived inconvenience of the metabolically controlled diet. Participants reported no adverse events related to the study protocol.

\section{Interpretation}

In the study presented here, replacement of $13 \%$ of total calories from carbohydrate with monounsaturated fat resulted in a $12.5 \%$ greater increase in HDL cholesterol over four weeks, without altering the substantial reduction in LDL cholesterol. The reductions in LDL cholesterol were considerable when expressed in terms of the reduction over the two months of metabolic diets (run-in plus portfolio): $35 \%$ for both the high and low monounsaturated fat treatments (Appendix 2). There was also a $6.5 \%$ greater reduction in the atherogenic index (ratio of total to HDL cholesterol ${ }^{9,22}$ ) for the dietary portfolio high in monounsaturated fat relative to the portfolio low in monounsaturated fat. The $12.5 \%$ increase in HDL cholesterol was of similar magnitude to that observed in two studies of gemfibrozil, in which HDL cholesterol concentration increased by $6 \%$ and $8 \%$, with corresponding reductions in the relative risk of cardiovascular disease of $22 \%$ and $23 \% .{ }^{23,24}$ The cardioprotective potential of HDL cholesterol has been reviewed recently. ${ }^{25}$

Table 3: Effect of dietary portfolios high and low in monounsaturated fatty acids (MUFA) on blood lipids, C-reactive protein and blood pressure in 24 study participants (data presented as means)

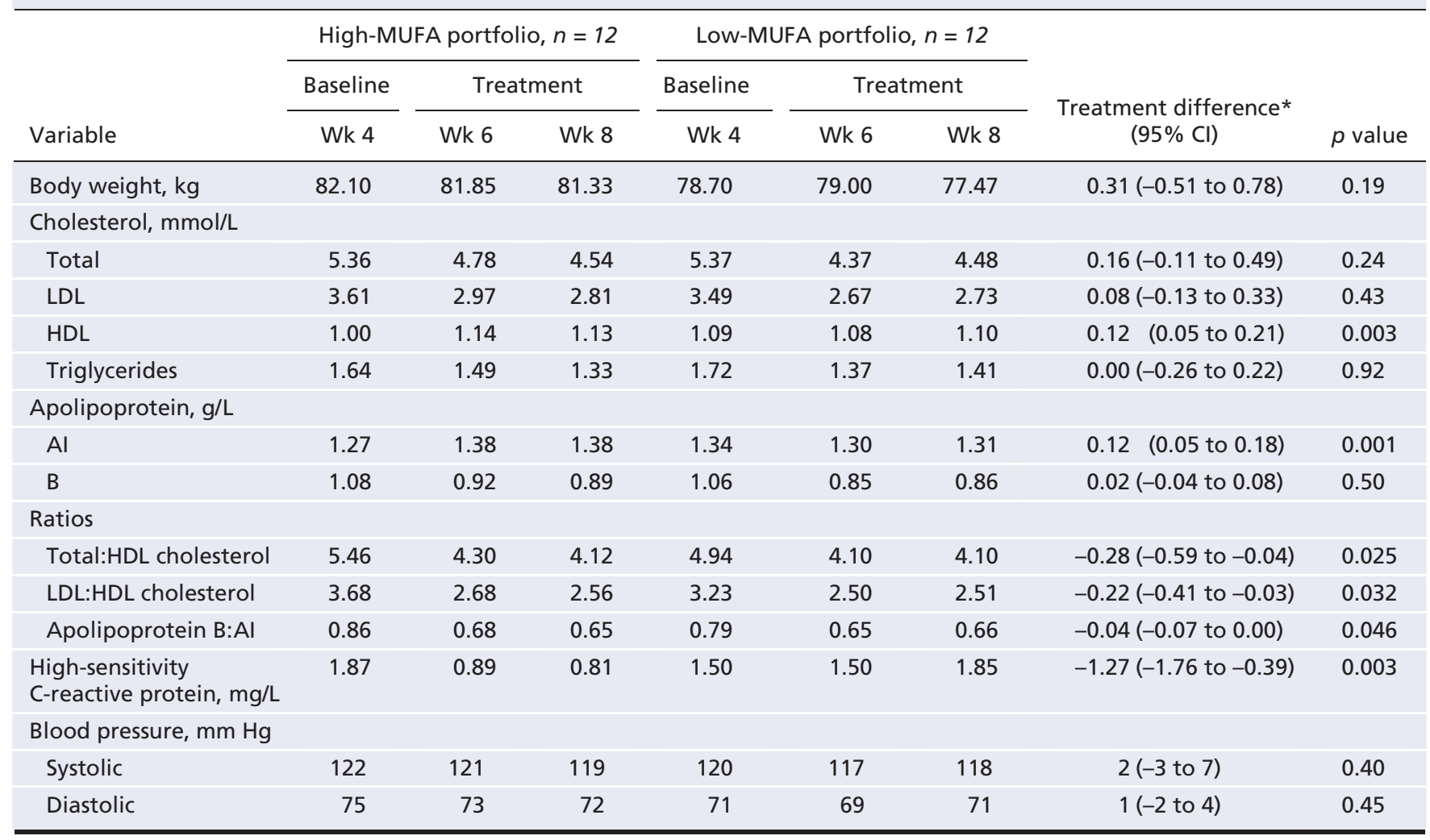

Note: $\mathrm{Cl}=$ confidence interval, $\mathrm{HDL}=$ high-density lipoprotein, $\mathrm{LDL}=$ low-density lipoprotein.

*Difference in change over time between high- and low-MUFA groups, by repeated-measures analysis. 
In our study, the addition of monounsaturated fat increased HDL cholesterol and therefore may further enhance the cardioprotective effect of a cholesterol-lowering dietary portfolio without diminishing its cholesterol-lowering effect.

The mechanisms by which monounsaturated fat increase HDL cholesterol are likely to be several. They may include the ability of monounsaturated fat to scavenge free radicals ${ }^{26,27}$ or reduce the synthesis of proinflammatory cytokines in adipose tissue and thus reduce the stimulus for hepatic synthesis of acutephase proteins such as C-reactive protein. This metabolic environment would also allow increased synthesis of negative acute-phase proteins, such as apolipoprotein AI, as was seen in the present study. Our data are consistent with such a hypothesis, in that the plasma concentration of C-reactive protein was reduced with the dietary portfolio high in monounsaturated fat. In addition, the displacement of dietary carbohydrates by monounsaturated fat is likely to result in less carbohydrateinduced hepatic synthesis of very-low-density lipoprotein triglyceride. ${ }^{28}$ The resulting lower concentration of very-low-density lipoprotein triglyceride, although not significant in the present study, may attenuate the impact of cholesteryl ester transfer protein in depleting cholesteryl ester in HDL, ${ }^{29,30}$ thereby contributing to a rise in plasma concentration of HDL cholesterol. It might also be predicted that the resulting triglyceride-poor, cholesterylester-rich HDL would be less rapidly lost from the circulation by tissue uptake than a triglyceride-rich cholesteryl-ester-poor par- ticle. ${ }^{28,31,32}$ This postulate is consistent with the observed increase in concentration of apolipoprotein AI with the dietary portfolio high in monounsaturated fat. ${ }^{33,34}$

Exercise and moderate alcohol consumption may be regarded as pleasurable ways of raising HDL cholesterol. Raising HDL cholesterol by increasing the intake of monounsaturated fat may also have dietary appeal, not only as part of the Mediterranean diet but also because olives, avocados, nuts, and canola and olive oils are potentially rich sources of monounsaturated fat. Weight loss and smoking cessation, although effective in raising HDL cholesterol, are more challenging for many people.

The strengths of this study included the large effect size and the dietary metabolic control, which ensured the uniform and very specific exchange of carbohydrate for monounsaturated fat in the diet for one treatment arm.

\section{Limitations}

This study had a relatively small number of participants, and they experienced relatively low weight loss (which nevertheless was similar for the two treatment groups). The prescriptive nature of the diet was another limitation, since adherence to a diet may be considerably less for a self-selected diet consumed under realworld conditions. Because of an error in our original power calculation, we predicted a smaller requirement for participants than our estimates of effect size and SD of effect, made at the time, would have predicted. However, this error in the original power
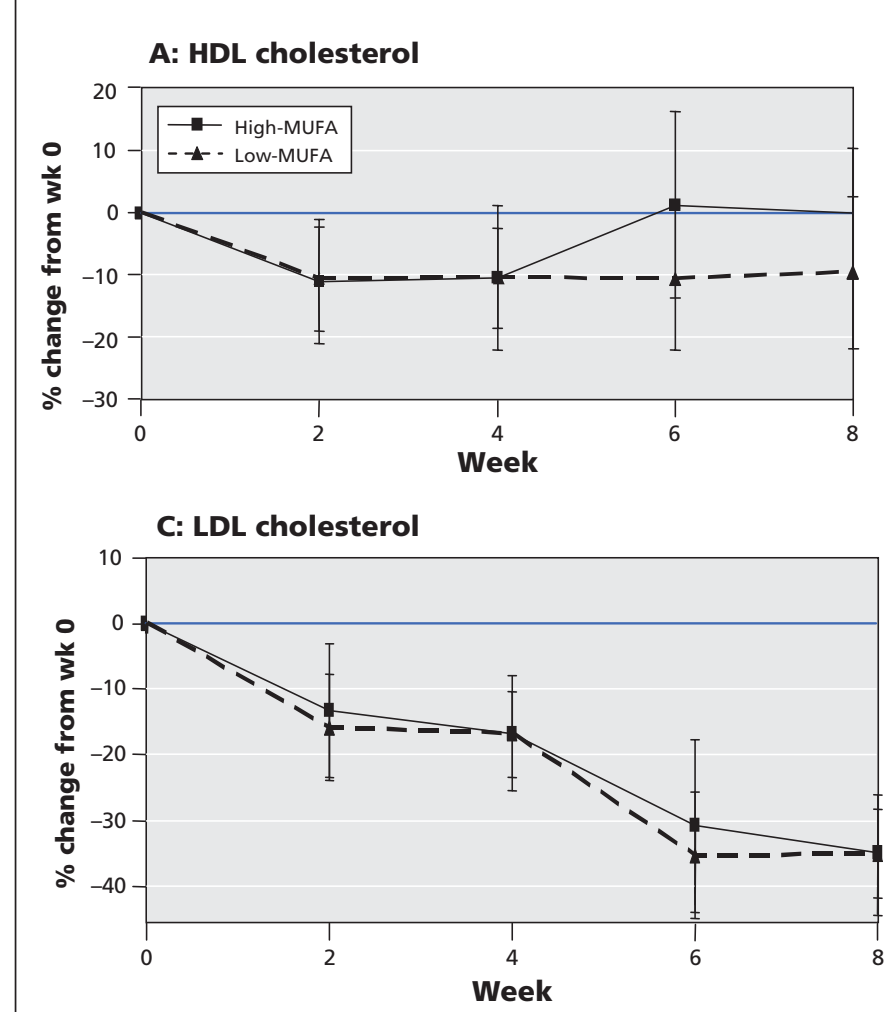

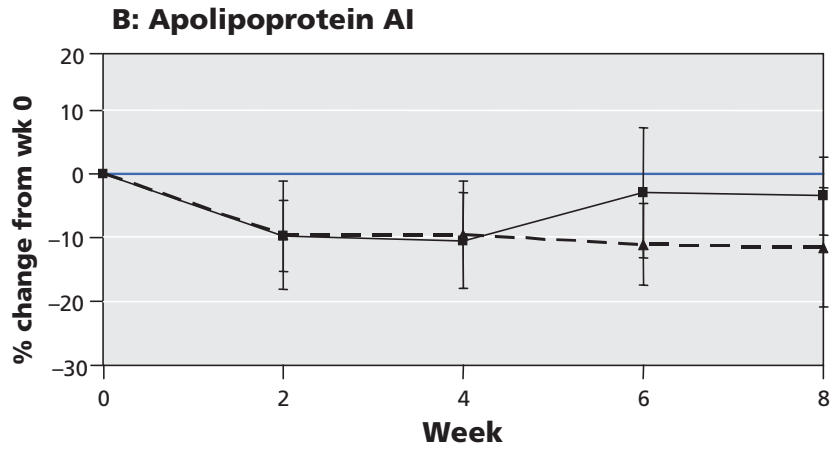

D: Apolipoprotein B

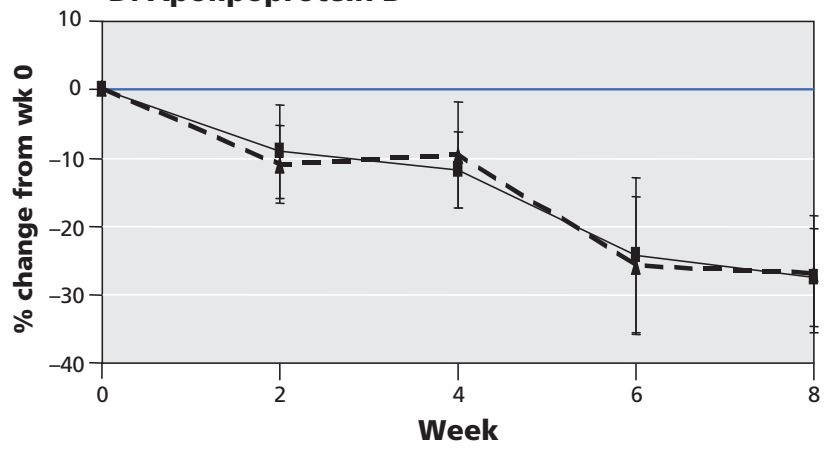

Figure 2: Mean percentage change (and standard deviation) from baseline in (A) high-density lipoprotein (HDL) cholesterol $(p=0.003)$, (B) apolipoprotein AI $(p=0.001)$, (C) low-density lipoprotein (LDL) cholesterol $(p=0.43)$ and (D) apolipoprotein B ( $p=0.50)$ with dietary portfolios having high and low levels of monounsaturated fatty acid (MUFA). Significance of differences between treatments was determined by repeated-measures analysis. 
calculation did not prevent detection of significant treatment differences in key outcomes (HDL cholesterol at $p=0.003$ and apolipoprotein $\mathrm{AI}$ at $p=0.001$ ), helped by the larger-thanexpected effect size and the use of repeated-measures analysis (the power calculation being based only on single measures).

\section{Conclusion}

The potential of an effective cholesterol-lowering diet to reduce the risk of cardiovascular disease may be significantly enhanced by inclusion of a moderate amount of monounsaturated fat. The long-term effect on self-selected diets remains to be determined, in terms of compliance and in terms of the lipid response and, ultimately, cardiovascular outcomes.

\section{This article has been peer reviewed.}

Competing interests: Dr. Jenkins is a consultant for Herbalife International, Nutritional Fundamentals for Health, Pacific Health Laboratories, Metagenics/Metaproteomics, Bayer Consumer Care, BENEO-Orafti, the Science Advisory Committee of Agriculture and Agri-food Canada, and the Canadian Agriculture Policy Institute and has received consulting fees from the Almond Board of California, the California Strawberry Commission, the Soy Advisory Board (Dean Foods), Kellogg Company, Quaker Oats, Procter \& Gamble and Olways Preservation Trust. He holds grants from Solae, Unilever, Loblaws Supermarkets, Barilla, Haine Celestial, the Sanitarium Company and BENEO-Orafti and a board membership with Herbalife International and has stock options for Pacific Health Laboraties Inc. His wife is a director of Glycemic Index Laboratories, Toronto, Ontario. Dr. Kendall has received a grant from the Canadian Institutes for Health Research, travel support from the Almond Board of California and partial salary support from research grants provided by Loblaws. Mr. Vidgen received salary funding from Dr. Jenkins's research group. Dr. Leiter has served as a consultant for Astra Zeneca, Merck, Pfizer, Roche, Solvay, Bristol Myers Squibb, Boehringer-Ingelheim, Eli Lilly, GlaxoSmithKline, Novartis, Novo Nordisk, Sanofi-Aventis and Servier; has received grants from Astra Zeneca, Merck, Pfizer, Roche, Bristol Myers Squibb, Eli Lilly, GlaxoSmithKline, Novartis, Novo Nordisk and Sanofi-Aventis; and has received honoraria from Astra Zeneca, Merck, Pfizer, Roche, Bristol Myers Squibb, BoehringerIngelheim, GlaxoSmithKline, Novartis, Novo Nordisk, Sanofi-aventis and Servier. Dr. Lamarche has received operating grants for activities unrelated to this article from the Canadian Institutes of Health Research and AFMNet. None declared for Ms. Chiavaroli, Dr. Wong, Dr. Lewis, Dr. Connelly and Dr. Josse.

Contributors: Dr. Jenkins and Dr. Kendall had full access to all of the data in the study and take responsibility for the integrity of the data and the accuracy of the data analysis. Dr. Jenkins, Dr. Wong, Dr. Kendall, Dr. Lewis, Mr. Vidgen, Dr. Leiter, Dr. Josse and Dr. Lamarche were responsible for study concept and design. Dr. Jenkins, Ms. Chiavaroli, Dr. Wong, Dr. Kendall and Mr. Vidgen were responsible for acquisition of data. Dr. Jenkins, Ms. Chiavaroli, Dr. Kendall, Dr. Lewis, Mr. Vidgen, Dr. Connelly, Dr. Josse and Dr. Lamarche were responsible for analysis and interpretation of data, and Mr. Vidgen performed the statistical analysis. All authors critically revised the manuscript for important intellectual content and approved the manuscript submitted for publication. Dr. Jenkins and Dr. Kendall obtained the funding. Ms. Chiavaroli, Dr. Wong and Dr. Kendall provided administrative, technical or material support. Dr. Jenkins, Ms. Chiavaroli, Dr. Wong, Dr. Kendall, Dr. Leiter and Dr. Josse supervised the study.

Funding: This study was supported by the Canadian Institutes of Health Research, the Canada Research Chair Program and Loblaws. Drs. Jenkins, Lewis and Lamarche were funded as Canada Research Chairs by the Government of Canada. Dr. Wong received a Doctoral Research Award and a Fellowship Award from the Canadian Institutes of Health Research. None of the funding organizations or sponsors played any role in the design and conduct of the study; in the collection, management, analysis and interpretation of the data; or in the preparation, review or approval of the manuscript.

\section{REFERENCES}

1. Grundy SM, Cleeman JI, Merz CN, et al. Implications of recent clinical trials for the National Cholesterol Education Program Adult Treatment Panel III guidelines [erratum published in: Circulation 2004;110:763]. Circulation 2004;110:227-39.

2. Executive Summary of the Third Report of the National Cholesterol Education Program (NCEP) Expert Panel on Detection, Evaluation, and Treatment of High Blood Cholesterol in Adults (Adult Treatment Panel III). JAMA 2001;285:2486-97.
3. Jenkins DJ, Kendall CW, Marchie A, et al. Effects of a dietary portfolio of cholesterollowering foods vs lovastatin on serum lipids and C-reactive protein. JAMA 2003;290:502-10

4. Jenkins DJ, Kendall CW, Faulkner DA, et al. Assessment of the longer-term effects of a dietary portfolio of cholesterol-lowering foods in hypercholesterolemia. Am J Clin Nutr 2006;83:582-91.

5. Barter P, Gotto AM, LaRosa JC, et al. HDL cholesterol, very low levels of LDL cholesterol, and cardiovascular events. N Engl J Med 2007;357:1301-10.

6. Gordon DJ, Probstfield JL, Garrison RJ, et al. High-density lipoprotein cholesterol and cardiovascular disease. Four prospective American studies. Circulation 1989;79:8-15.

7. Nicholls SJ, Tuzcu EM, Sipahi I, et al. Statins, high-density lipoprotein cholesterol, and regression of coronary atherosclerosis. JAMA 2007:297:499-508.

8. Garfagnini A, Devoto G, Rosselli P, et al. Relationship between HDL-cholesterol and apolipoprotein A1 and the severity of coronary artery disease. Eur Heart $J$ 1995; 16:465-70.

9. Anderson KM, Wilson PW, Odell PM, et al. An updated coronary risk profile. A statement for health professionals. Circulation 1991;83:356-62.

10. Grundy SM. Comparison of monounsaturated fatty acids and carbohydrates for lowering plasma cholesterol. $N$ Engl J Med 1986;314:745-8.

11. Mensink RP, Katan MB. Effect of monounsaturated fatty acids versus complex carbohydrates on high-density lipoproteins in healthy men and women. Lancet 1987;1:122-5.

12. Hu FB, Stampfer MJ. Nut consumption and risk of coronary heart disease: a review of epidemiologic evidence. Curr Atheroscler Rep 1999;1:204-9.

13. Halton TL, Willett WC, Liu S, et al. Low-carbohydrate-diet score and the risk of coronary heart disease in women. $N$ Engl J Med 2006;355:1991-2002.

14. Ainsworth BE, Haskell WL, Leon AS, et al. Compendium of physical activities: classification of energy costs of human physical activities. Med Sci Sports Exerc 1993;25:71-80.

15. Harris J, Benedict FG. A biometric study of basal metabolism in man. Washington (DC): Carnegie Institute of Washington; 1919.

16. Shetty PS, Henry CJ, Black AE, et al. Energy requirements of adults: an update on basal metabolic rates (BMRs) and physical activity levels (PALs). Eur J Clin Nutr 1996;50(Suppl 1):S11-23.

17. Warnick GR, Kimberly MM, Waymack PP, et al. Standardization of measurements for cholesterol, triglycerides, and major lipoproteins. Lab Med 2008;39:491-5.

18. Jose C, Pinheiro DMB. Mixed-effects models in S and S-PLUS. New York (NY): Springer; 2004.

19. R Development Core Team. $R$ : a language and environment for statistical computing. R Foundation for Statistical Computing; 2008.

20. Bates D, Sarkar D. lme4: linear mixed-effects models using S4 classes. R package version 0.999375-28. 2008.

21. Conservative ANOVA tables in Imer [discussion thread]. Last updated 2006 Dec. 2. Available: http://rwiki.sciviews.org/doku.php?id=guides:Imer-tests (accessed 2010 May 5).

22. Kinosian B, Glick H, Garland G. Cholesterol and coronary heart disease: predicting risks by levels and ratios. Ann Intern Med 1994;121:641-7.

23. Manninen V, Tenkanen L, Koskinen P, et al. Joint effects of serum triglyceride and LDL cholesterol and HDL cholesterol concentrations on coronary heart disease risk in the Helsinki Heart Study. Implications for treatment. Circulation 1992:85:37-45.

24. Robins SJ, Collins D, Wittes JT, et al. Relation of gemfibrozil treatment and lipid levels with major coronary events: VA-HIT: a randomized controlled trial. JAMA 2001:285:1585-91.

25. Di Angelantonio E, Sarwar N, Perry P, et al. Major lipids, apolipoproteins, and risk of vascular disease. JAMA 2009;302:1993-2000.

26. Nalsen C, Vessby B, Berglund L, et al. Dietary (n-3) fatty acids reduce plasma F2 isoprostanes but not prostaglandin F2alpha in healthy humans. J Nutr 2006; 136:1222-8

27. Ashton EL, Best JD, Ball MJ. Effects of monounsaturated enriched sunflower oil on CHD risk factors including LDL size and copper-induced LDL oxidation. $J$ Am Coll Nutr 2001;20:320-6.

28. Rashid S, Watanabe T, Sakaue T, et al. Mechanisms of HDL lowering in insulin resistant, hypertriglyceridemic states: the combined effect of HDL triglyceride enrichment and elevated hepatic lipase activity. Clin Biochem 2003;36:421-9.

29. Lewis GF. Determinants of plasma HDL concentrations and reverse cholesterol transport. Curr Opin Cardiol 2006;21:345-52.

30. Tall AR. Cholesterol efflux pathways and other potential mechanisms involved in the athero-protective effect of high density lipoproteins. J Intern Med 2008;263:256-73.

31. Lewis GF, Rashid S, Uffelman KD, et al. Mechanism of HDL lowering in insulin resistant states. Adv Exp Med Biol 2001;498:273-7.

32. Tall AR. Plasma high density lipoproteins. Metabolism and relationship to atherogenesis. J Clin Invest 1990;86:379-84.

33. Mensink RP, Zock PL, Kester AD, et al. Effects of dietary fatty acids and carbohydrates on the ratio of serum total to HDL cholesterol and on serum lipids and apolipoproteins: a meta-analysis of 60 controlled trials. Am J Clin Nutr 2003;77:1146-55.

34. Appel LJ, Sacks FM, Carey VJ, et al. Effects of protein, monounsaturated fat, and carbohydrate intake on blood pressure and serum lipids: results of the OmniHeart randomized trial. JAMA 2005;294:2455-64.

Correspondence to: Dr. David J.A. Jenkins, Clinical Nutrition and Risk Factor Modification Centre, St Michael's Hospital, 61 Queen St.E, Toronto ON M5C 2T2; cyril.kendall@utoronto.ca 